AperTO - Archivio Istituzionale Open Access dell'Università di Torino

\title{
The complexity of theory of mind
}

\section{This is the author's manuscript}

Original Citation:

Availability:

This version is available http://hdl.handle.net/2318/142845

since

Published version:

DOI:10.1016/j.concog.2008.12.007

Terms of use:

Open Access

Anyone can freely access the full text of works made available as "Open Access". Works made available under a Creative Commons license can be used according to the terms and conditions of said license. Use of all other works requires consent of the right holder (author or publisher) if not exempted from copyright protection by the applicable law. 


\section{(3) \\ UNIVERSITÀ DEGLI STUDI DI TORINO}

This is an author version of the contribution published on:

Questa è la versione dell'autore dell'opera:

CONSCIOUSNESS AND COGNITION, Volume: 18, Issue: 1, Published: MAR 2009

DOI: 10.1016/j.concog.2008.12.007

The definitive version is available at:

La versione definitiva è disponibile alla URL:

http://cogprints.org/6817/1/2009-Thomas2-ConscCog.pdf 


\title{
The complexity of theory of mind
}

\author{
Francesca M. Bosco \\ Livia Colle \\ Maurizio Tirassa \\ University of Torino, Department of Psychology and Center for Cognitive Science, via Po 14, \\ 10123 Torino, Italy
}

University of Torino, Neuroscience Institute of Torino, Italy

A growing body of literature views Theory of mind (ToM) as a complex activity involving related but different abilities (e.g., Harrington, Seigert \& McClure, 2005; Saxe, Moran, Scholz \& Gabrieli, 2006; Tirassa, Bosco \& Colle, 2006). This reflects in the types of experimental tasks that have been proposed in recent years for the assessment of ToM in normal and abnormal populations, some of which focus on the ability to understand visual or other perceptual cues as hints to another individual's mental states (e.g., Baron-Cohen, Wheelwright, Hill, Raste \& Plumb 2001, Rutherford, Baron-Cohen \& Wheelwright 2002; Golan, Baron-Cohen, Hill \& Rutherford, 2007) and others on the comprehension of complex mental states as encapsulated in short stories or linguistic questions (e.g., Happè, 1994; Baron-Cohen, O'Riordan, Stone, Jones \& Plaitsed, 1999; Pons \& Harris, 2000).

Let us discriminate two facets of labels like ToM or mindreading. One is the situated ability to understand and react to someone's mental states ("this thug is planning to assault me - I'd better let him see that I carry a knife"); roughly, it is manifestations of this facet that are explored by the first type of experimental tasks mentioned above. Another is the retrospective reconsideration of one's own or another individual's ways or ability to cope with mentalistic social cognition ("I always feel in danger when people conceal their thoughts"); again roughly, it is manifestations of this facet that are explored by the second type of tasks. Each facet may be further analyzed according to more detailed considerations like the distinction between an egocentric and an allocentric perspective or between the various types of epistemic, volitional and other mental states that humans may understand. Particularly in developmental psychology, the difference between on-line and retrospective aspects of ToM has also been compared to the distinction between implicit and explicit knowledge or functioning of ToM (e.g., Clements \& Perner, 1994); however, the latter distinction is often used intuitively, leaving many theoretical questions open (Dienes \& Perner, 1999).

To sum up, ToM may be viewed as a sophisticated mental activity which allows to quickly form and handle local, situated ideas about oneself or the others in a specific moment as well as larger ideas about how one and the others live and cope in general across any number of different and possibly hypothetical situations. Both facets of ToM have been a focus of research, but, to our knowledge, the conceptual and theoretical relations between them have never been worked out to any satisfactory level of detail and, as discussed above, the experimental paradigms with which they have been studied are quite different. The Th.o.m.a.s. interview (Bosco et al., 2009) is meant to investigate the retrospective facet of ToM, based on a theoretically-driven decomposition thereof that aims at bringing its diversity and complexity into light. There is no way of doing this without recurring to the interviewee's deliberate introspection and discursive abilities.

It is possible that, as Badgaiyan (2009) suggests, schizophrenia might affect differently the two facets of ToM. Yet, there is no reason to think that either one has a systematically more important causal role than the other in the mental life of a healthy or schizophrenic person. By contrast, they influence each other: the retrospective ability has to build in part upon the reconsideration of previous episodes and situations in which the on-line interpretation of mental states has yielded some interesting lesson to learn; conversely, the on-line interpretation of the current situation has to be informed in part by the individual's general worldview and biography as well as by the outcomes of and reflections upon situations met in the past. We believe that the retrospective facet of ToM plays a fundamental role and that it is crucial to our understanding of social cognition in schizophrenia and elsewhere.

Another issue raised by Badgaiyan concerns the role that memory, language and IQ may play in ToM activities and in the relevant experimental tasks. Truly, certain such activities and tasks require an adequate level of non-ToM cognitive functioning; this, however, is necessary but not sufficient for a satisfactory ToM 
performance (Lysaker, Dimaggio, Buck, Carcione, \& Nicolò, 2007), nor can ToM be reduced to these measurements of cognitive efficiency. Therefore, all that an empirical study of ToM must guarantee is that the subjects are above threshold for the cognitive functions needed to solve the task proposed. This is what we made in our study: the participants were recruited based on their IQ, as investigated with the WAIS-R, which also includes subscales for the assessment of working memory and language comprehension.

The third and final issue raised by Badgaiyan that we have the space to tackle here concerns the inconsistency in the data available about the impairments of ToM in different symptomatological subtypes of schizophrenia. It appears from the literature (e.g., Brüne, 2005; Harrington, Seigert \& McClure, 2005) that the degree of ToM impairment varies according to the type of schizophrenic symptoms, ranging from being present only rarely, if at all, in patients with hallucinations and delusions to being frequent in patients with paranoid symptoms and almost universal in patients with behavioral symptoms.

In principle, this might be due to a variety of causes and bring to a corresponding variety of consequences in our understanding of schizophrenia. It should be noticed, however, that most tests used in this field view ToM as an undivided function; or, more precisely, that they typically explore only one of its dimensions, namely third-person, allocentric ToM. Currently, therefore, it cannot be excluded that different symptomatological subtypes of schizophrenia may also have different profiles of ToM impairment. We are not claiming that this necessarily is the case; however, this is the kind of issues for the exploration of which a test like Th.o.m.a.s., devised for the parallel exploration of several dimensions of ToM, is properly equipped. While we did not find any significant difference between egocentric and allocentric ToM in our subjects, it has to be noticed that we were able to employ only a comparatively small number of participants. Clearly, further studies are needed concerning this issue.

Finally, we would like to thank Rajendra D. Badgaiyan for the thoughtful attention that he devoted to our work.

\section{References}

Badgaiyan, R. D. (2009). Theory of Mind and schizophrenia. Consciousness and Cognition, this issue.

Baron-Cohen, S., O'Riordan, M., Stone, V., Jones, R., \& Plaitsed, K. (1999). Recognition of faux pas by normally developing children and children with Asperger syndrome or high-functioning autism. Journal of Autism and Developmental Disorders, 29, 5, 395-406.

Baron-Cohen, S., Wheelwright, S., Hill, J., Raste, Y., \& Plumb, I. (2001). The "Reading the mind in the eyes" test revised version: A study with normal adults, and adults with Asperger syndrome or high-functioning autism. Journal of Child Psychology and Psychiatry, 42, 241-251.

Bosco, F.M., Colle, L., De Fazio, S., Bono, A., Ruberti, S., \& Tirassa, M. (2009). Th.o.m.a.s.: An exploratory assessment of Theory of Mind in schizophrenic subjects. Consciousness and Cognition, this issue.

Brüne, M. (2005). "Theory of mind" in schizophrenia: A review of the literature. Schizophrenic Bulletin, 31, 21-42.

Clements, A.W., \& Perner, J. (1994). Implicit understanding of false belief. Cognitive Development, 9, 377-397.

Dienes, Z., \& Perner, J. (1999). A theory of implicit and explicit knowledge. Behavioral and Brain Sciences, 22, 735-755.

Golan, O., Baron-Cohen, S., Hill, J. J., \& Rutherford, M. D. (2007). The "Reading the mind in the voice" test revised: A study of complex emotion recognition in adults with and without autism spectrum conditions. Journal of Autism and Developmental Disorders, 37, 1096-1106.

Happé, F. (1994). An advanced test of Theory of mind. Journal of Autism and Developmental Disorders, 24, 129-154.

Harrington, L., Siegert, R. J., \& McClure, J. (2005). Theory of mind in schizophrenia: A critical review. Cognitive Neuropsychiatry, 10, 249-286.

Lysaker, P. H., Dimaggio, G., Buck, K. D., Carcione, D., \& Nicolò G. (2007). Metacognition within narratives of schizophrenia: Associations with multiple domains of neurocognition. Schizophrenia Research, 93, 278-287.

Pons, F., \& Harris, P.L. (2000). TEC (Test of Emotion Comprehension). Oxford University Press, Oxford.

Rutherford, M. D., Baron-Cohen, S., \& Wheelwright, S. (2002). Reading the mind in the voice: A study with normal adults and adults with Asperger syndrome and high functioning autism. Journal of Autism and Developmental Disorders, 32, 189-94.

Saxe, R., Moran, J. M., Scholz, J., \& Gabrieli, J. (2006). Overlapping and non-overlapping brain regions for theory of mind and self reflection in individual subjects. Scan, 1, 229-234.

Tirassa, M., Bosco, F. M., \& Colle, L. (2006). Rethinking the ontogeny of mindreading. Consciousness and Cognition, 15, $197-217$. 